\title{
MEASUREMENT OF YEAST GROWTH IN GRAPE JUICE WITH A FIBRE OPTIC NEPHELOMETER
}

\author{
PAUL R. MONK AND PETER J. COSTELLO \\ The Australian Wine Research Institute, Private Mail Bag, \\ Glen Osmond, SA 5064, Australia
}

(Received August 29, 1983)

\begin{abstract}
A fibre optic nephelometer was evaluated for use in measuring yeast cell numbers during the aerobic growth of yeast in grape juice. The response of the nephelometer to yeast cells in suspension decreased with increasing sugar concentration, and the decrease was dependent on the yeast population. Yeast cell number could be corrected from the observed nephelometer response with a calibration factor dependent on sugar concentration. Yeast populations as determined from the nephelometer response were compared to those determined by haemocytometer and optical density.
\end{abstract}

The use of yeast starter cultures, aerobically grown and harvested in the stationary growth phase, is a significant factor in determining the rate of sugar attenuation during the anaerobic fermentation of grape juice (1). The time taken for a starter culture to reach the stationary phase will vary with yeast strain and the nutritional and physical environment. Therefore methods for continuously recording the stage of growth of a starter culture are helpful in determining the optimum time to add the culture to grape juice.

Cell populations can be measured directly with a haemocytometer or electronic particle counter and indirectly by either cell dry weight and protein content or turbidity with a spectrophotometer or nephelometer. Each method reflects different properties of a culture, but to obtain a measure of cell population by means of indirect methods a calibration factor must be developed, which will depend on the instrumentation and the physiological state of the culture (2).

Turbidity of a cell suspension measured with transmitted light in a spectrophotometer is related to cell mass, whereas the ratio of scattered light to the incident light as measured with a nephelometer is proportional to cell numbers (3). Fibre optic probes have been designed to monitor continuously the turbidity of microbial suspensions by both transmitted (4) and reflected light $(5,6)$. When transmitted light is employed yeasts give a response different from that of bacteria, which is attributed to their larger volume. VECHER et al. (7) have shown that the turbidity 
of yeast cells suspended in water varied considerably with cell size when measured with a nephelometer.

Previous determinations of yeast populations by nephelometry have been made in media of low sugar concentration, particularly when compared to grape juice, which contains about $200 \mathrm{~g} / \mathrm{l}$ of total sugar. Cell volume, and hence turbidity, is influenced by sugar concentration and therefore varies during the fermentation of grape juice. In this report, aerobic yeast growth in grape juice is monitored with a nephelometer fitted with a fibre optic probe suitable for the continuous recording of microbial growth. The performance of such a nephelometer is compared to that of other classical methods, such as spectrophotometric measurement of turbidity, direct counting of yeast cells with a haemocytometer and measurement of sugar degradation.

\section{MATERIALS AND METHODS}

Yeast strain. Sacharomyces cerevisiae, laboratory strain AWRI 114, was utilized.

Media. Yeast culture was maintained on grape juice agar slants; $140 \mathrm{~g} / \mathrm{l}$ total sugar, $2 \%$ agar. The grape juice in this experiment was of the Pedro Ximinez variety, supplied by Wynns Seaview Winery, South Australia; $140 \mathrm{~g} / \mathrm{l}$ total sugar; $\mathrm{pH} 3.4 ; 7 \mathrm{~g} / \mathrm{l}$ total acid. Diammonium hydrogen orthophosphate (DAP, $0.4 \mathrm{~g} / l)$, was added to the juice which was then sterile filtered $(0.45 \mu$ membrane).

Nephelometer. The nephelometer was manufactured by Analite (Mitcham, Vic., Australia). The nephelometer was adjusted to zero response with the probe placed in glass-distilled water and calibrated against a calibrator unit supplied with the instrument. The turbidity is reported in nephelometer turbidity units (NTU).

Yeast cell cultivation and harvesting. Yeast cells used for the nephelometer calibration were grown in juice in a sterilised $1 l$ capacity Biotec fermentor (LKB Produkter, Bromma, Sweden), incubated at $28^{\circ}$ with aeration and magnetically stirred. The yeast culture was grown until cell numbers reached the stationary phase of growth $\left(250-300 \times 10^{6}\right.$ cells $\left./ \mathrm{ml}\right)$ as determined by haemocytometer. Cells were harvested by centrifugation, washed with distilled water and centrifuged again before use in calibration suspensions.

Calibration of nephelometer response to yeast cell density in glucose suspension medium. Freshly harvested yeast cells were suspended in nine duplicate levels of cell density ranging from $0.41-3.09 \times 10^{5} / \mathrm{ml}$ in $20 \mathrm{ml}$ of aqueous glucose suspension media ranging from $0-200 \mathrm{~g} / \mathrm{l}$ in duplicate increments of $25 \mathrm{~g} / \mathrm{l}$. Nephelometer response was recorded for the respective cell densities and glucose concentrations. The nephelometric response was also recorded for yeast cells at a density of $2 \times 10^{8} / \mathrm{ml}$ suspended in an aqueous solution of $200 \mathrm{~g} / \mathrm{l}$ of fructose and of a 
mixture of glucose and fructose both at $100 \mathrm{~g} / \mathrm{l}$.

Spectral turbidity of yeast cells in glucose suspension media. Freshly harvested yeast cells were suspended in water to provide a range of optical densities between 0-0.6 units when measured in $10 \mathrm{~mm}$ pathlength cuvettes at $650 \mathrm{~nm}$. A portion of each suspension was centrifuged and the cell pellet resuspended in a similar volume of $200 \mathrm{~g} / l$ glucose solution. The optical density $\left(\mathrm{OD}_{650}\right)$ of yeast cells suspended in water and in glucose solution was recorded.

Aerobic growth of yeast in grape juice. Juice $(700 \mathrm{ml})$ was aseptically transferred into a sterilized $1 l$ capacity Biotec fermentor (LKB Produkter, Bromma, Sweden), incubated at $28^{\circ}$ and magnetically stirred and aerated. The juice was inoculated with freshly harvested yeast cells to give a final cell density of $5 \times 10^{6}$ cells $/ \mathrm{ml}$. During aerobic growth cell numbers were counted in a haemocytometer, the $\mathrm{OD}_{650}$ was measured after dilution in $0.85 \%$ saline and the turbidity of the medium was continuously monitored with the nephelometer. At each sampling time total solids was measured with a hand-held refractometer, and glucose and fructose were determined enzymatically (8).

\section{RESULTS}

Effect of sugar level in the suspension medium on the nephelometric response to yeast cells

Preliminary work indicated that the response of the nephelometer to a given density of yeast cells varied with the sugar level of the suspending medium. Therefore it became necessary to prepare a calibration curve from which the observed nephelometer response could be corrected to take into account the sugar concentration of the medium at the time of measurement.

For each yeast cell suspension between 0.41 and $3.09 \times 10^{8}$ cells $/ \mathrm{ml}$, the nephelometer response decreased as the glucose concentration in the medium increased (Fig. 1). The response was linear up to $200 \mathrm{~g} / \mathrm{l}$ of glucose for cell densities below $0.8 \times 10^{8} \mathrm{ml}$ and up to $125-150 \mathrm{~g} / \mathrm{l}$ of glucose for cell densities above $0.8 \times 10^{3} / \mathrm{ml}$. The decrease in nephelometer response as a function of increasing sugar level was greater at higher yeast cell densities.

The slope of the linear regression between nephelometer response and glucose level for each cell density obtained from Figure 1 was calculated to obtain nephelometer sensitivity. The sensitivity, expressed as NTU per $\mathrm{g} / l$ of glucose, decreases with increasing cell density (Fig. 2). At cell densities below $0.4 \times 10^{s} / \mathrm{ml}$ there is a negligible change in nephelometer sensitivity as a function of sugar level, i.e. nephelometer response to yeast cells at levels lower than $0.4 \times 10^{8} / \mathrm{ml}$ is not affected by glucose concentration.

With the same set of results the observed nephelometer response was linear with increasing cell density for each glucose concentration. The equation of linear regression for each glucose concentration is expressed in the form $y=m x+c$ 


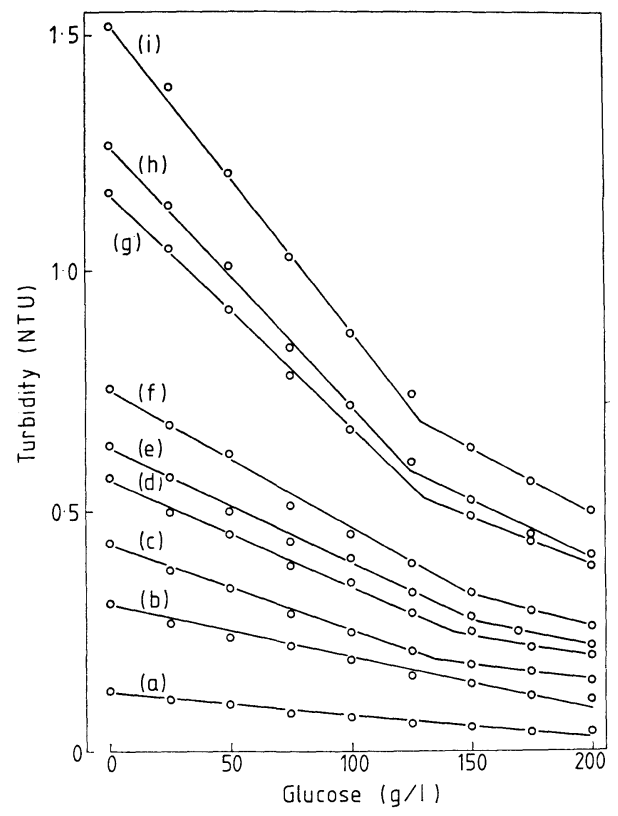

Fig. 1. Nephelometer response by yeast suspended in different glucose solutions at cell densities of 0.41 (a), 0.85 (b), 1.00 (c), 1.22 (d), 1.58 (e), 2.01 (f), 2.52 (g), 2.64 (h) and $3.09 \times 10^{5}$ cells $/ \mathrm{ml}$ (i).

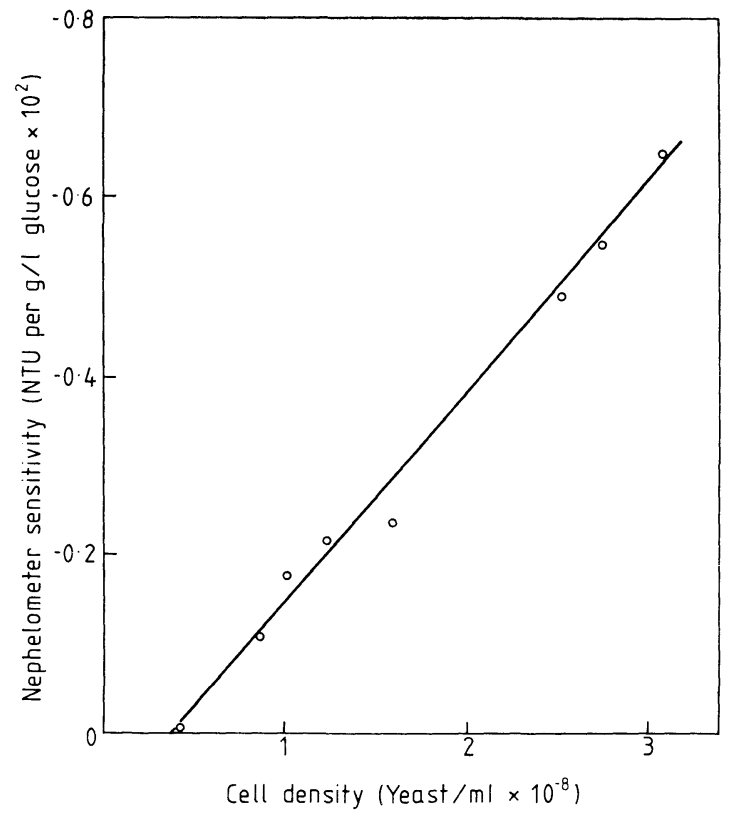

Fig. 2. Decrease in nephelometer sensitivity obtained from nephelometer response to the yeast cell densities shown suspended in glucose solutions ranging from 0 to $200 \mathrm{~g} / \mathrm{l}$. 


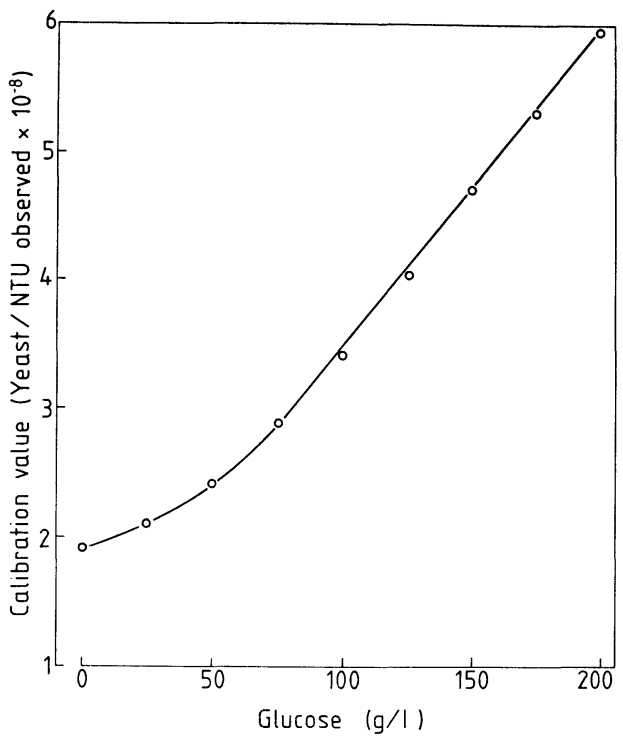

Fig. 3. Calibration value given as the slope of the linear regressions relating yeast cell density to the observed nephelometer response measured in aqueous glucose solution.

where $y$ is the cell density, $x$ the observed nephelometer response, $c$ the ordinate intercept in cells $\times 10^{3}$, and $m$ the slope of the regression and calibration constant for a given glucose concentration with units of cells $\times 10^{s} / \mathrm{NTU}$. The correlation coefficient for the regressions ranged between 0.990 and 0.997 for each glucose concentration between 0 and $200 \mathrm{~g} / l$, and the mean of the intercept (c) was essentially constant, $0.22 \pm 0.023 \times 10^{5}$ cells $/ \mathrm{ml}$. The slope of each linear regression (calibration value) is plotted against glucose concentration in Fig. 3. The calibration constant shows a linear increase between 80 and $200 \mathrm{~g} / \mathrm{l}$ of glucose and approaches a constant value below $80 \mathrm{~g} / \mathrm{l}$ of glucose.

No significant difference was found between the nephelometer response obtained for yeast cells suspended in either glucose, fructose or equal mixtures of both sugars at the same total concentration of $200 \mathrm{~g} / l$.

Spectral turbidity of yeast cells suspended in water and in $200 \mathrm{~g} / \mathrm{l}$ glucose solution

From the slope of the linear regression, it was found that the $\mathrm{OD}_{650}$ value of yeast cells suspended in glucose solution was $73.5 \%$ of that in water (results not shown).

Measurement of aerobic yeast growth in grape juice

The optical density $\left(\mathrm{OD}_{650}\right)$, cell numbers determined with a haemocytometer, nephelometric response and cell numbers derived from nephelometric response during aerobic yeast growth in grape juice are shown in Fig. 4. The rate of yeast 


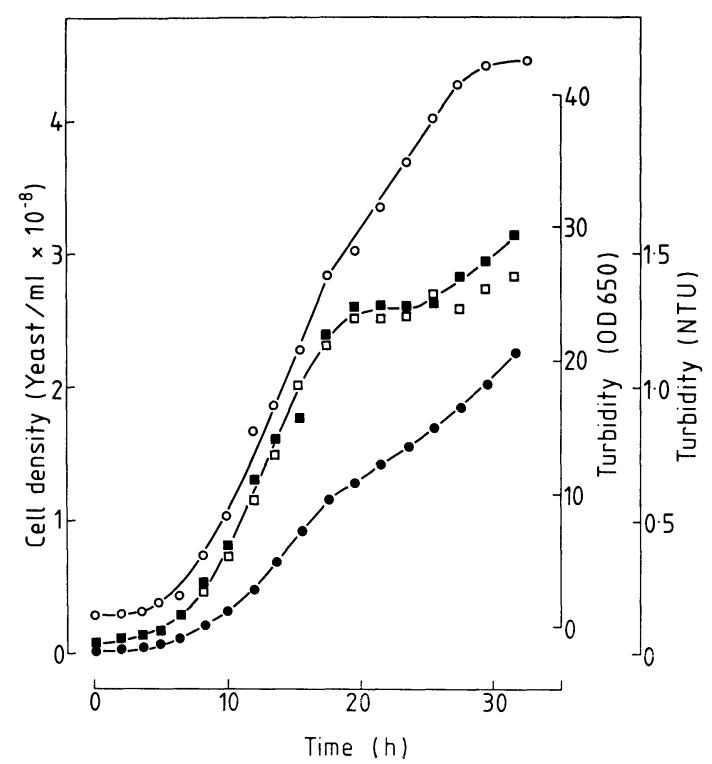

Fig. 4. Aerobic growth of yeast in grape juice at $28^{\circ}$ measured by optical density $(0)$, cell numbers $(\mathbf{D})$, observed nephelometer response $(\bigcirc)$, and cell numbers calculated from the observed nephelometer response and the calibration value for the total sugar concentration at the time of the observation $(\beth)$.

growth, as determined by the $\mathrm{OD}_{650}$ value and by cell numbers determined with a haemocytometer, increased exponentially until $12 \mathrm{hr}$ after inoculation; the specific growth rates were 0.41 and $0.44 \mathrm{hr}^{-1}$, respectively. The culture entered a stationary phase between 18 and $26 \mathrm{hr}$ after inoculation as determined by counting cell numbers; cell numbers further increased up to $32 \mathrm{hr}$. The rate of yeast growth, as determined by the $\mathrm{OD}_{650}$ value, decreased after the initial exponential growth, however, showed a linear increase between 16 and $28 \mathrm{hr}$, with no further increase after about $30 \mathrm{hr}$, which corresponded to the cell population entering the stationary phase.

The nephelometer response increased slowly during yeast growth giving a small inflection in the response curve at about $18 \mathrm{hr}$ after inoculation, the time corresponding to the cell population entering the stationary phase and the $\mathrm{OD}_{650}$ measurement indicating the start of a linear increase.

At the time each nephelometer response was recorded the total sugar concentration (glucose + fructose) of the medium was determined; the nephelometer calibration value corresponding to each sugar level was obtained from Fig. 3. The calibration constant, $m$, multiplied by the observed nephelometer response $(x)$ gave a yeast cell density which was corrected by subtracting $0.22 \times 10^{3}$ cells $/ \mathrm{ml}$, the constant higher value $(c)$ found with all sugar concentrations in the linear regressions $y=m x+c$ relating observed nephelometer response to cell density. 


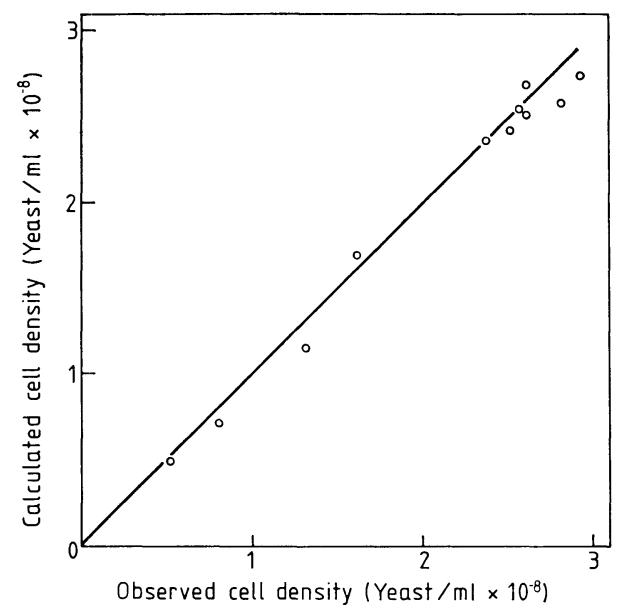

Fig. 5. Correlation between the cell density calculated from the observed nephelometric response and the cell density counted in a haemocytometer.

Yeast numbers during aerobic growth obtained by nephelometry or by counting with a haemocytometer were similar until $26 \mathrm{hr}$ after inoculation; the nephelometer response then indicated a smaller population (Fig. 4). The correlation between the two methods was linear (Fig. 5), with the regression having a slope of 0.96 and correlation coefficient of 0.993 . The rate of sugar catabolism increased exponentially between 8 and $16 \mathrm{hr}$ with a specific degradation rate of $0.34 \mathrm{hr}^{-1}$, and then remained constant at $5.4 \mathrm{~g} / \mathrm{l}$ per hr until $30 \mathrm{hr}$ after inoculation (Fig. 6). The constant rate of sugar catabolism corresponded with the time of the linear increase in the $\mathrm{OD}_{650}$ and the stationary growth phase indicated by the cell population (Fig. 4).

During aerobic yeast growth in grape juice a linear correlation was obtained between the total dissolved solids content of the ferment as measured with a hand held refractometer and sugar content measured enzymatically. The relationship was linear over the range $50-200 \mathrm{~g} / l$ of sugar with the corresponding refractive index measurement giving 100-200 g/l of solids.

\section{DISCUSSION}

The sensitivity of both the spectral and nephelometric methods for estimation of yeast cell populations increases with decreasing sugar concentration. Continuous measurement by nephelometry of the number of cells of yeast growing in juice of high sugar concentration must be corrected for the sugar level to obtain actual cell numbers. A calibration constant is required for each sugar concentration. Cell numbers obtained from the nephelometer response to the aerobically growing culture agreed with that obtained by haemocytometer, however, the 


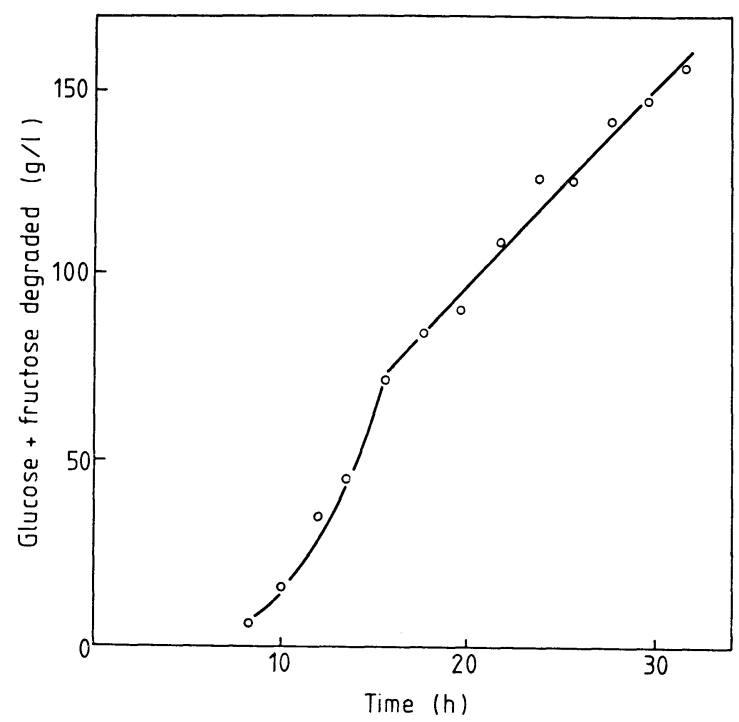

Fig. 6. Rate of total sugar degradation (glucose and fructose) during aerobic yeast growth in grape juice.

necessity to determine sugar concentration negates any time advantage gained from the continuous recording of turbidity. Measurement of optical density on undiluted suspensions would encounter an error similar to that as for nephelometry due to sugar concentration.

The sugar content of the medium, measured as total solids by a hand held refractometer, was directly proportional to the total sugar concentration determined enzymatically as glucose and fructose, but significantly higher values were obtained by the refractometer method. The measure of total solids can be obtained rapidly and, although not an accurate estimate of sugar concentration, could be used to calibrate the nephelometer probe. The utility of the nephelometer probe would be improved if coupled with the continuous measurement of sugar content by refractive index. The relationship between sugar concentration and the nephelometer calibration constant is accurately defined (Fig. 3) and could be incorporated in the instrumentation to automatically correct the observed nephelometric response to record directly yeast cell density. Such a modification is currently being evaluated.

The physiological properties of a yeast starter culture, by which the anaerobic fermentation of grape juice is initiated, influence yeast growth and the rate of sugar attenuation. Sterols and unsaturated fatty acids are formed in the cell under aerobic conditions (8) and determine the extent of subsequent yeast growth and sugar attenuation (9). The reserve materials in yeast, glycogen and trehalose, are mainly accumulated during the approach to the stationary growth phase and are used by yeast to maintain viability under starvation conditions (10) and as an 
initial energy source when the yeast is inoculated into wort $(11,12)$. In the present work, the $\mathrm{OD}_{650}$ value, a measure of cell mass, increased significantly during the stationary growth phase of the yeast culture growing aerobically in grape juice (Fig. 4), which is attributed to the accumulation of reserve materials. A yeast starter culture prepared in grape juice is, therefore, physiologically suitable for initiating the anaerobic fermentation of grape juice after the stationary phase has been reached.

The rate of sugar catabolism in grape juice (Fig. 6) followed the initial increase in cell numbers and optical density, but the specific rate of sugar catabolism of $0.34 \mathrm{hr}^{-1}$ was significantly different from the specific growth rate of the yeast calculated from cell numbers $\left(0.41 \mathrm{hr}^{-1}\right)$ and $\mathrm{OD}_{6.50}$ measurements $\left(0.44 \mathrm{hr}^{-1}\right)$. With balanced growth the rate of substrate utilisation and cell proliferation would proceed at the same rate (13). During the stationary phase, sugar catabolism continued at a constant rate similar to the increase in optical density.

The stage of growth is the most significant parameter in determining the time at which a yeast starter culture should be inoculated into grape juice, however, continuous measurement of cell numbers by nephelometry is of limited value unless corrected for the effect of changing sugar concentration on the nephelometric response.

\section{REFERENCES}

1) M. Strydon, A. Kirschbaum and A. Tromp, S. Afr. J. Enol. Vitic., 3, 23 (1982).

2) J. R. Pringle and J.-R. Mor, In Methods in Cell Biology, Vol. XI, ed. by D. M. Prescott, Academic Press, New York (1975), p. 141.

3) F. Kavanagh, In Analytical Microbiology, ed. by F. Kavanagh, Academic Press, New York (1963), p. 141.

4) S. A. Robrish, A. F. LeRoy, B. M. Chassey, J. J. Wilson and M. I. Krichevsky, Appl. Microbiol., 21, 278 (1971).

5) C. W. Hancher, L. H. Thacker, and E. F. Phares, Biotechnol. Bioeng., 16, 475 (1974).

6) T. L. Smith and L. D. Witter, Appl. Environ. Microbiol., 44, 1476 (1982).

7) A. S. Vecher, K. Y. Levitman and I. M. Granshchikova, Pishch. Tekhnol., 2, 160 (1969).

8) Boehringer Mannheim $\mathrm{GmbH}$, Methods of Enzymatic Food Analysis, Mannheim, West Germany (1982).

9) H. Suomalainen and T. Nurminen, J. Inst. Brew. London, 82, 218 (1976).

10) V. Aries and B. H. Kirsop, J. Inst. Brew. London, 83, 220 (1977).

11) S. H. Lillie and J. R. Pringle, J. Bacteriol., 143, 1384 (1980).

12) A. Panek, Arch. Biochem. Biophys., 100, 422 (1963).

13) D. E. Quain, P. A. Thurston, and R. S. Tubb, J. Inst. Brew. London, 87, 108 (1981). 